\title{
(6) OPEN ACCESS \\ Save LIVES technical package: 22 interventions that could make a difference
}

\author{
Margaret Mary Peden, ${ }^{1}$ Meleckidzedeck Khayesi ${ }^{2}$
}

\begin{abstract}
${ }^{1}$ The George Institute for Global Health UK, Oxford, UK

${ }^{2}$ Department for

the Management of

Noncommunicable Diseases,

Disability, Violence \& Injury

Prevention, World Health

Organization, Geneva,

Switzerland
\end{abstract}

Correspondence to Dr Margaret Mary Peden, The

George Institute for Global Health, Oxford, OX1 3QX, UK; margie.peden@georgeinstitute. ox.ac.uk

Received 9 May 2018

Accepted 14 May 2018

Published Online First

4 June 2018

\section{ABSTRACT}

The Save LIVES: a road safety technical package was produced and launched in May 2017 by the WHO to support road safety decision makers and practitioners in their efforts to significantly reduce the number of road traffic deaths in their countries. This Special Feature explains the process used to develop the package and how and why the 22 interventions were included. It concludes by encouraging researchers and practitioners to tailor their road safety packages to their own realities by following five practical steps.

\section{INTRODUCTION}

Road traffic crashes lead to the loss of around 1.3 million lives ${ }^{1}$ and cause non-fatal injuries to as many as 50 million people around the world each year. ${ }^{2}$ Nearly half $(49 \%)$ of the people who die on the world's roads are pedestrians, cyclists and motorcyclists. Road traffic crashes are the main cause of death among people aged between 15 and 29 years. ${ }^{2}$ In addition to the grief and suffering they cause, road traffic crashes constitute an important public health and development problem with significant health and socioeconomic costs.

Aimed at halving road traffic deaths and injuries by 2020 and providing access to safe, affordable, accessible and sustainable transport systems for all by 2030, Sustainable Development Goal (SDG) targets 3.6 and 11.2 provide a powerful focus to galvanise governments and the international community into action on road safety policy. ${ }^{3}$ The challenge is to seize this opportunity and to significantly scale up implementation of road safety measures at national, subnational and urban levels. In this context, the Save LIVES: a road safety technical package was produced and launched in May 2017 by the WHO to support road safety decision makers and practitioners in their efforts to significantly reduce the number of road traffic deaths in their countries. ${ }^{4}$

\section{HOW IT WAS DEVELOPED}

The development of this package was based on a framework by Justen and colleagues published in 2014, which involves six interrelated stages, namely, defining objectives and targets, creating an inventory of measures, assessing the package, modifying the package and implementing and evaluating the package. ${ }^{5}$ A meeting of 24 external experts and 5 WHO technical staff was held on 9-10 February 2016 to discuss whether there was a need to develop a road safety technical package of interventions to assist countries implement quick wins as expected in the SDG target. Consensus was reached, and the group went on to agree that the Global Plan for the Decade of Action for Road Safety 2011-2020 should be used as a basis from which to focus messages around a smaller set of priority interventions. ${ }^{6}$ There was also consensus on the need to prioritise speed management within this package as it is considered a unifying component across all the five pillars in the global plan. The need to include quick wins in infrastructure and to ensure that the package addressed the high burden among vulnerable road users was also emphasised. A small working group of experts was constituted to develop the package. A preliminary list of over 50 'good practices' was identified by WHO technical staff and reviewed by the small working group. This initial list was examined against published evidence on effective measures, in particular through systematic reviews and summary reports that have been compiled ${ }^{7-11}$ and trimmed to 44 specific interventions.

The 44 specific interventions were further reviewed by researchers and practitioners against a set of criteria on effectiveness, cost, acceptability, capacity and institutional complexity to implement, technical complexity, timescale of implementation and time from implementation of the measure to the time its effect is realised.

The effectiveness of the interventions was also examined with respect to their contribution to reducing road traffic fatalities and serious injuries and changing behaviour. Each intervention was assessed for effectiveness as follows:

- Proven: evidence from robust studies such as randomised controlled trials, systematic reviews or case-control studies shows that these interventions are effective in reducing road traffic fatalities and injuries or in bringing about desired change in behaviour.

- Promising: evidence from robust studies shows that some road safety benefits have resulted from these interventions, but further evaluation from diverse settings is required and caution is needed when implementing them.

- Insufficient: evaluation of an intervention has not reached a firm conclusion about its effectiveness because of a lack of evidence.

Feedback from the review and intense discussion within the small working group led to the list of 44 specific interventions being revised, merged and consolidated into 22 measures, which are presented in table 1.

\section{CORE COMPONENTS AND INTERVENTIONS}

The core components of the Save LIVES technical package are Speed management, Leadership, Infrastructure design and improvement, Vehicle safety 


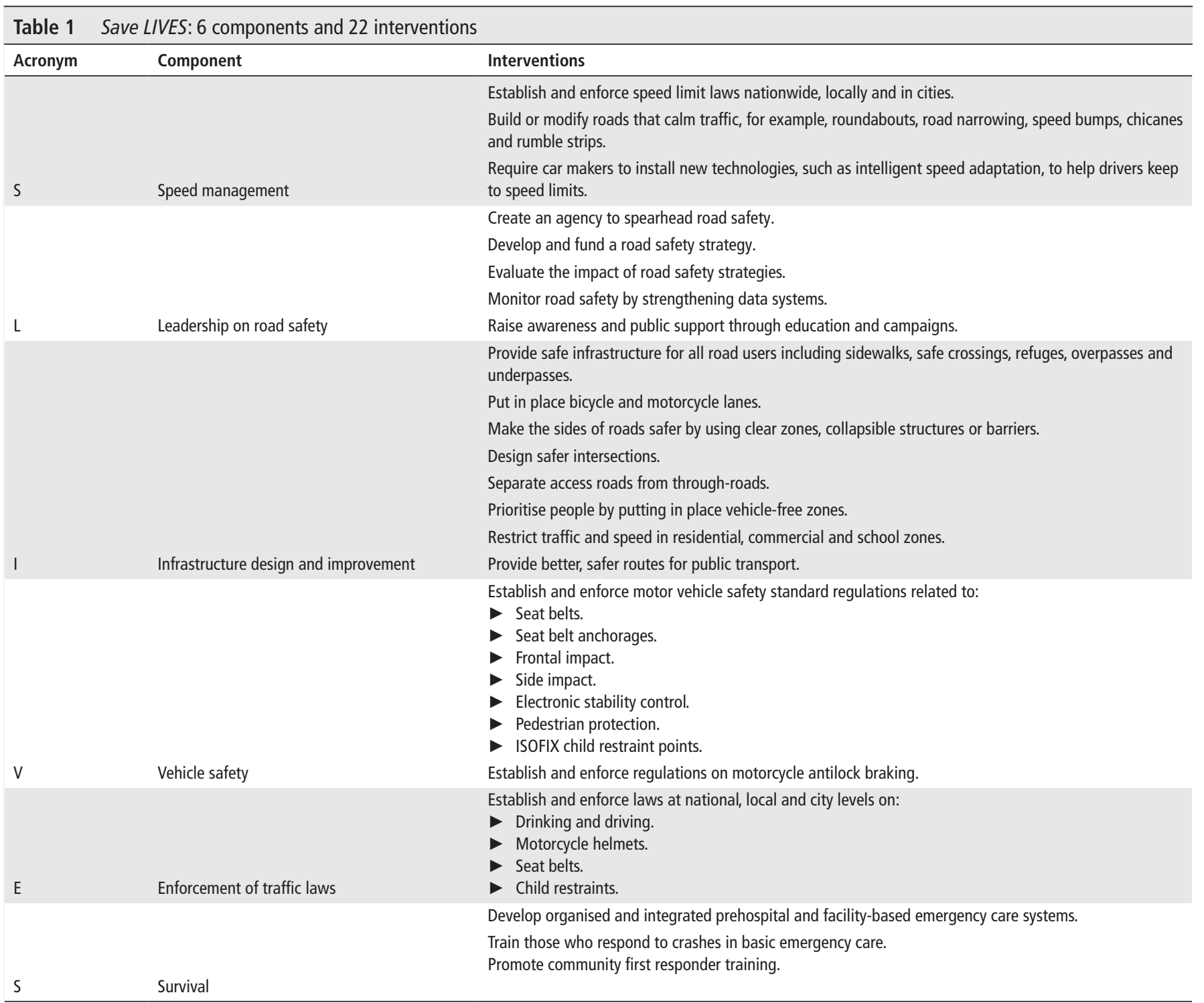

Source: WHO.4

standards, Enforcement of traffic laws and postcrash Survival (table 1). Each component of Save LIVES is associated with priority interventions that will assist road safety decision makers and practitioners in making tangible and sustained progress in reducing road traffic injuries in the next 5 years and beyond. These 6 components and 22 interventions are inter-related and need to be implemented in an integrated manner, following the Safe System approach, to effectively address the problem of road traffic deaths and injuries.

\section{CONCLUSION}

Since the reality of road safety policy implementation differs across countries, this package should not be seen as a one-sizefits-all solution but rather as a guide to support decisions for scaling up the road safety efforts.

To make effective use of this the package, countries need to do the following:

- Determine where they are now by conducting a situational assessment of their road safety programmes.

- Establish where they want to be in the next 5 years and beyond by setting targets and indicators (see http://www.who.int/ violence_injury_prevention/road_traffic/road-safety-targets/ en/ for recently agreed global targets and indicators for road safety risk factors and service delivery).

- Establish how they will get to their target by preparing strategic plans of action.

- Take practical steps to get where they want to be by consistently implementing their strategic plans of action.

- Monitor and evaluate the implementation of their strategic plans of action.

The Save LIVES package has been translated into the five other UN languages and is available at: http://www.who.int/violence injury_prevention/publications/road_traffic/save-lives-package/ en/

Contributors MMP and MK jointly wrote the article. The Save LIVES report was developed at WHO when MMP was coordinator of the Unintentional Injury Prevention Unit and MK led the report development.

Funding This short report is based on a document that was made possible through funding from Bloomberg Philanthropies and US Centers for Disease Control and Prevention.

Competing interests None declared.

Consent Not required.

Provenance and peer review Commissioned; internally peer reviewed. 
Open access This is an Open Access article distributed in accordance with the Creative Commons Attribution Non Commercial (CC BY-NC 4.0) license, which permits others to distribute, remix, adapt, build upon this work non-commercially, and license their derivative works on different terms, provided the original work is properly cited and the use is non-commercial. See: http://creativecommons.org/ licenses/by-nc/4.0/

(c) Article author(s) (or their employer(s) unless otherwise stated in the text of the article) 2018. All rights reserved. No commercial use is permitted unless otherwise expressly granted.

\section{REFERENCES}

1 WHO. Global Health Estimates 2015: Deaths by Cause, Age, Sex, by Country and by Region, 2000-2015. Geneva, Switzerland: World Health Organization, 2016. Available from. http://www.who.int/healthinfo/global_burden_disease/estimates/en/index1. html.

2 WHO. Global status report on road safety 2015. Geneva, Switzerland: World health organization, 2015.
3 UN. Transforming our world: the 2030 agenda for sustainable development. New York: United Nations, 2015.

4 WHO. Save LIVES: A road safety technical package. Geneva, Switzerland: World Health Organization, 2017.

5 Justen A, Fearnley N, Givoni M, et al. A process for designing policy packaging: Ideals and realities. Transportation Research Part A: Policy and Practice 2014;60:9-18.

6 WHO. Global Plan for the Decade of Action for Road Safety 2011-2020. Geneva, Switzerland: World Health Organization, 2011.

7 Bunn F, Collier T, Frost C, et al. Traffic calming for the prevention of road traffic injuries: systematic review and meta-analysis. Inj Prev 2003:9:200-4.

8 Retting RA, Ferguson SA, McCartt AT. A review of evidence-based traffic engineering measures designed to reduce pedestrian-motor vehicle crashes. Am J Public Health 2003:93:1456-63.

9 Elvik R, Vaa T, Hoye A, et al. The handbook of road safety measures: Emerald Group Publishing, 2009

10 Peden M, Scurfield R, Sleet D, et al. World report on road traffic injury prevention. Geneva: World Health Organization, 2004.

11 HCM2010. Transportation Research Board. Washington, DC: National Research Council, 2010 